\title{
REIVINDICACIÓN DEL MODERNISMO EN LAS SONATAS DE VALLE-INCLÁN
}

\author{
Peggy von Mayer Chaves \\ Universidad de Costa Rica
}

Las Sonatas de Don Ramón María del Valle-Inclán se publicaron en los siguientes años: Sonata de Otoño, 1902; Sonata de Estío, 1903; Sonata de Primavera, 1904; Sonata de Invierno, 1905. Desde que fueron editadas hasta nuestros días, han sido objeto de crítica profusa y constante. La abundante bibliografía que constituye el material crítico en torno de las Sonatas es extensa; está conformada por una diversidad de estudios y monografías, publicados en libros y revistas especializados.

En términos generales, el discurso crítico se mantiene en la consideración de que las Sonatas son un simple ejercicio estético o literatura de evasión. En efecto, un sector de la crítica le reclama a Valle-Inclán que se haya imbuido en una estética "decadente", ignorando el problema de España. En términos similares se pronuncian Jorge Guillén, Guillermo de la Torre y Pedro Salinas, Leopoldo Alas “Clarín” y Joaquín Dicenta, entre otros.

Ortega y Gasset critica las Sonatas diciendo que la parte modernista de la obra produce "cierta reluctancia", debido a la "irrealidad pura", la "elusión de realidades mezquinas, escape hacia un mundo imaginario en donde todo es posible, al menos todo lo que no entre en colisión con perentorios imperativos morales". ${ }^{1}$ Y agrega (1961:25):

\begin{abstract}
¡Cuánto me regocijaré el día en que abra un libro nuevo del señor Valle-Inclán sin tropezar con princesas rubias que hilan en ruecas de cristal, ni ladrones gloriosos, ni inútiles incestos! Cuando haya concluido la lectura de ese libro probable, y dando placentero sobre él unas palmaditas, exclamaré: 'He aquí que don Ramón del Valle-Inclán se deja de bernardinas y nos cuenta cosas humanas, harto humanas, en su estilo noble de escritor bien nacido.
\end{abstract}

Antonio Risco justifica esa huída imaginativa diciendo que Valle se encuentra incómodo con la realidad circundante, porque el mundo se le antoja "grosero, prosaico, mostrenco, ridículo; es decir, esperpéntico". ${ }^{2}$ También asegura que cuando Valle escribe las Sonatas, su espíritu está ya más allá del modernismo. Esta perspectiva de lejanía le permite contemplarlo desde fuera, con una actitud de revisión crítica que conlleva ya en germen la perspectiva esperpéntica. ${ }^{3}$

Eugenio de Nora expresa que Valle "escribe formalmente como modernista, espiritualmente como decadente, sádico, perverso, etc., pero todo ello con afectación, 'desde fuera', por cansancio de lo mostrenco anterior, por moda -un tanto rezagada- o por afán de singularidad". ${ }^{4}$ 
Por su parte, Allen Phillips considera que las Sonatas representan una cumbre de la prosa modernista, pero las ubica en un plano ligeramente inferior a las realizaciones posteriores de Valle-Inclán. Reconoce el virtuosismo estilístico del autor, a pesar de su "preciosismo y amaneramiento exquisito".

Melchor Fernández Almagro afirma que las Sonatas poseen un estilo "que reverbera en la superficie de la expresión, pero que tiene su fondo, su raíz, sus motivos, en un concepto poético del mundo y de la vida y de la función que al interpretar una y otra cumple el arte."

Por su parte, Greenfield opina, siguiendo a Ortega y Gasset, que en las Sonatas, ValleInclán se da a la deshumanización del arte:

Lo que encontramos en el primer período valleinclanesco es, en suma, un impulso deshumanizante, o sea la voluntad de estilizar, reforzada por un espíritu de juego artístico y por una relativa impasibilidad moral y social ante la temática. En todo esto ya están las raíces de la definitiva voluntad de deshumanizar deformando que madura a partir de 1918 . $^{7}$

Carlos Seco Serrano se opone a esta tesis, afirmando que "el camino que escoge para expresar la fórmula política del 98 -el rechazo de la España oficial-, no es a través de una apelación regeneracionista o democrática, ni invocando la realidad oculta tras los convencionales telones de la 'farsa canovista', sino refugiándose en 'la otra España' -más que imposible- representada por el retablo medieval y caballeresco del carlismo."

Mientras que, desde otra perspectiva, José Antonio Maravall encuentra en el modernismo y romanticismo de Valle-Inclán una forma de protesta frente a la sociedad, y la presencia de una instancia ética superior, antes que ser una simple cuestión estética. ${ }^{9}$

Rodolfo Cardona y Anthony Zahareas, después de una prolija revisión del material crítico que se ha generado en torno de la obra de Valle-Inclán, manifiestan que España no ha desarrollado una crítica inteligente en cuanto al examen de la literatura moderna y, por consiguiente, muchos problemas complejos, como la literatura del absurdo y de lo grotesco, han quedado sin estudiar:

Empresarios conservadores y críticos sin imaginación, imbuidos de su espíritu tradicional de la literatura social y de tesis dentro de un marco naturalista, se espantaron de su humor un tanto escabroso, de su tono sardónico, de su vulgaridad sensual, y de sus ataques irreverentes contra las instituciones tradicionales como la Monarquía, el militarismo y la iglesia. En la España de su tiempo abundan los reaccionarios en materia de estética, incapacitados para comprender los experimentos literarios de Valle-Inclán, sus innovaciones teatrales, que expresaban abiertamente su hostilidad: sus experimentos fueron tachados de excéntricos; su arte puro y cuidadosamente construido se repudiaba por irresponsable; sus realidades grotescas se miraban como si fuesen literatura efectista; sus experimentos lingüísticos con la distorsión como si fuesen juegos de un complejo artificio; su traviesa y extravagante personalidad se consideraba como algo meramente frívolo y su comportamiento como decadente. ${ }^{10}$ 
La cita de estos autores, aunque extensa, tiene la virtud de condensar los grandes lineamientos conceptuales de lo que ha sido la crítica que ha generado la vasta y compleja producción valleinclanesca.

Ciertamente, se observa que la mayor parte de la crítica en relación con las Sonatas se caracteriza por estar enmarcada dentro de la lectura asistemática, la cual se rige por criterios de regulación ideológica, doxológica; se fundamenta en análisis apriorísticos, empíricos, y está marcada en gran medida por un impresionismo subjetivo. Esta situación se presenta a pesar de la diversidad de marcos teóricos, criterios estéticos, cognoscitivos e ideológicos que se distinguen en el material estudiado.

Como puede verse en los pocos ejemplos antes citados, algunos de los contemporáneos de Valle-Inclán, cuyo proyecto ideológico los comprometía directamente con el problema de España, le achacaron su encasillamiento en un mundo de estética, y criticaron que se mantuviera al margen de la realidad española. Desde esta perspectiva, consideraron que la estética modernista atiende únicamente a los preciosismos de la expresión, al imperativo del arte por el arte, con lo cual se constituye casi en un obstáculo que hay que salvar y del que hay que distanciarse para poder lograr una perspectiva adecuada de la realidad histórica. Esta actitud de la crítica se debe, primordialmente, al hecho de considerar el objeto estético como inoperante en la medida en que no se constituya en reflejo de la realidad.

Este trabajo intenta demostrar la inadecuación de estos juicios apriorísticos, probando que las Sonatas evidencian una lúcida actitud crítica de la sociedad española del siglo XIX, manifiesta en la visión irónica del Marqués de Bradomín. La perspectiva irónica del protagonista descubre a los personajes de la corte y el clero, indaga los oscuros orígenes de su alcurnia, las falsas apariencias y los juegos ocultos, la religiosidad exterior y sus transgresiones interiores, los privilegios y desmanes, en suma, su verdadera naturaleza humana.

\section{La ironía del Marqués de Bradomín}

La ironía es una de las características ontológicas relevantes del Marqués de Bradomín. Bradomín es irónico porque su cerebración consciente del mundo que le rodea le permite cierta distancia del objeto, y su aguda percepción intelectual le permite cuestionar el código de valores de la sociedad a la que pertenece.

La ironía es un tropo de pensamiento o metalogismo, entendido como aquél en que la técnica retórica se ejerce respectivamente sobre los núcleos sémicos del discurso y sobre su valor lógico. Es "una figura de pensamiento porque afecta a la lógica ordinaria de la expresión. Consiste en oponer, para burlarse, el significado a la forma de las palabras en oraciones, declarando una idea de tal modo que, por el tono, se pueda comprender otra contraria (...) La descodificación del metalogismo requiere el análisis del referente, pues su sentido abarca una realidad ubicada más allá del texto, en un contexto que puede ser discursivo o extralingüístico". "1

María Pérez hace ver que la mayoría de las prácticas significantes tienden a reproducir una ideología dominante; pero que a esos textos se oponen otros que intentan desenmascarar o criticar esa ideología de forma contestataria y desacralizadora, para lo cual emplean el recurso de la ironía. ${ }^{12}$ 
Ahora bien, la ironía requiere de parte del destinatario una participación activa en el proceso de desenmascaramiento, así como la adquisición de una "conciencia en la constitución del nuevo sentido que se le da a la realidad, que le ha sido presentada bajo la máscara impuesta por la ideología dominante."13 A este respecto, las Sonatas constituyen textos desacralizadores y acervamente críticos de la sociedad española de la época que recrean, fundamentados en una postulación esencial incisivamente sarcástica.

En la Sonata de Primavera, el Marqués de Bradomín establece una severa crítica del mundo aparencial en el que se mueven tanto los miembros de la nobleza como los del clero, expertos en el arte de ocultar las verdaderas intenciones. Este doble juego de verdad/apariencia se manifiesta claramente en la Sonata de Primavera, a través de las actitudes de las personas que están en el Palacio Gaetani durante la agonía y muerte del obispo de Betulia. El narrador emplea para crear esta irrealidad los verbos "aparentar" y "parecer", para expresar atinadamente la hipocresía y la falsedad:

Todos aparentaban una gran pesadumbre, y parecían de antemano edificados por aquella confesión que intentaba hacer ante ellos el moribundo obispo de Betulia. $(S P, 9)$

Y es que todos, en una u otra medida, fingen lo que no son: la princesa Gaetani se oculta tras una apariencia de bondad, pero actúa con saña en el suceso de la supuesta violación a María Rosario, mandando a hacer un hechizo al Marqués para hacerle perder su virilidad. Con esta acción pone en evidencia, además, su ausencia de cristianismo, que repudia la venganza, y su creencia en la superstición popular. Esta es la misma señora que anteriormente se preocupaba por la salud del alma del Marqués. De su mayordomo se puede decir lo mismo: toma una apariencia de beatitud y fe religiosa, pero resulta ruin y alevoso.

Actitudes semejantes se detectan en miembros del clero. Durante la visita de Bradomín al Palacio Gaetani, como Guardia Noble de Su Santidad, portador del capelo cardenalicio para el agonizante obispo de Betulia, su visión irónica se enfoca sobre la falsa apariencia del Colegial Mayor, Monseñor Antonelli, como se colige del siguiente fragmento:

La verdad es que cuanto manaba de sus labios parecía lleno de ciencia teológica y de unción cristiana...(...) Adivinaba por primera vez en mi vida, todo el influjo galante de los prelados romanos, y acudía a mi memoria la leyenda de sus fortunas amorosas. Confieso que hubo instantes donde olvidé la ocasión, el sitio y hasta los cabellos blancos que peinaban aquellas nobles damas, y que tuve celos, celos rabiosos del Colegial Mayor. $(S P, 13)$

Además de la apariencia de sabiduría, Bradomín insinúa sutilmente la posible relación amorosa del Colegial con las damas del Palacio Gaetani. A la muerte del obispo, ambos cumplen con el ritual verbal, exterior, de lamentar el deceso, el cual no les conmueve en absoluto, mucho menos a Antonelli, cuya mano "parecía reclamar la pastoral amatista" $(S P, 12)$; o sea, que probablemente tenía aspiraciones de ocupar el puesto del recientemente fallecido obispo: 
...-¡Qué desgracia, Marqués!

-¡Muy grande, Monseñor!

Nos miramos de hito en hito, con un profundo convencimiento de que fingíamos por igual, y nos separamos. $(S P, 14)$

Ahora bien, Monseñor Antonelli, acorde con la inclinación amorosa que anteriormente había observado el Marqués, es en verdad un hombre mundano; en la siguiente secuencia, que ocurre durante el cortejo fúnebre, el prelado se ofrece a "servir de guía" al joven. El recurso irónico que se emplea aquí es un tropo de dicción o metasemema, puesto que invierte el sentido de las palabras próximas:

Monseñor Antonelli me hizo sitio a su derecha, y con humildad, que me pareció estudiada, comenzó a dolerse de lo mucho que con la muerte de aquel santo y de aquel sabio perdía el Colegio Clementino. Yo a todo asentía con un vago gesto, y disimuladamente miraba a las ventanas llenas de mujeres. Monseñor tardó poco en advertirlo, y me dijo con una sonrisa tan amable como sagaz:

-Sin duda no conocéis nuestra ciudad.

-No, Monseñor.

-Si permanecéis algún tiempo entre nosotros y queréis conocerla, yo me ofrezco a ser vuestro guía. ¡Está llena de riquezas artísticas! $(S P, 16)$

En efecto, se sobreentiende que las "riquezas artísticas" a las que alude el prelado son las mujeres a las cuales Xavier está mirando.

En la cita que se da a continuación, la pompa y el boato de los clérigos que forman parte del cortejo fúnebre son descritos mediante el juego de palabras llamado dilogía o anfibología, el cual permite la doble lectura:

(...) el sol abrileño, joven y rubio como un mancebo, brillaba en las vestiduras sagradas, en la seda de los pendones y en las cruces parroquiales con un alarde de poder pagano. $(S P, 17)$

La frase "alarde de poder pagano" se puede referir tanto al sol como a las vestiduras sagradas, la seda de los pendones y las cruces, generalmente de oro o plata. Esta segunda lectura denuncia el lujo excesivo de los miembros del clero, reforzando la ironía mediante el adjetivo "sagradas" que califica a "vestiduras".

La conformación de esa Comunidad religiosa se ironiza mediante el contraste de la serie de adjetivos referentes a los novicios y a los profesos, que se ofrece a continuación:

En la puerta de la iglesia, alumbrándose con cirios, esperaba la Comunidad dividida en dos largas hileras. Primero los novicios, pálidos, ingenuos, demacrados. Después los profesos, sombríos, torturados, penitentes. (SP, 17)

Hay toda una connotación de degradación espiritual progresiva, que en la primera serie (pálidos, ingenuos, demacrados), gira en torno al segundo adjetivo: los novicios son ingenuos, 
no han profesado; se podría suponer que la emoción del momento los empalidece y que están demacrados por la vigilia de la vela. Mientras que los profesos son calificados de "sombríos, torturados, penitentes". ¿Acaso los tortura el pecado y por eso están en penitencia y son sombríos?

El anticlericalismo del Marqués se manifiesta a lo largo de todas las obras, mediante expresiones cargadas de ironía: en las Sonatas desfilan "abates barbilindos que dejaban un rastro de almizcle" ( $S E, 44)$, cuyas características señalan cierta femineidad; una criada indulgente "como un buen jesuita" $(S O, 93)$ para sus amores pecaminosos con Concha; un obispo, su tío el Marqués de Tor, que tenía reconocidos veintisiete bastardos" ( $S O, 113)$; un "santo, lleno de caridad", que había recogido en su palacio a una viuda, y hasta un caballo "viejo, prudente, reflexivo y grave como un Pontífice". (SO, 109)

El Marqués de Bradomín es irónico también al referirse a los privilegios de algunas congregaciones, que denotan jerarquías internas dentro de la clerecía:

¡Oh, regalada holgura, eclesiástica opulencia, jocunda glotonería, siempre añorada, del Real e Imperial Monasterio de Sobrado! $(S O, 134)$

Pero no todos los miembros del clero gozan de los mismos privilegios. En el convento de las Comendadoras Santiaguistas, Fray Lope Castellar no celebra misa con el mismo vino de Su Ilustrísima:

Este humilde fraile celebra su misa con un licor menos delicado. Sin embargo, todo es sangre de Nuestro Señor Jesucristo. $(S E, 65)$

La mujer dedicada a la vida monástica tampoco escapa a la perspectiva irónica del Marqués. Al referirse a la Madre Abadesa de dicho convento, protectora del bandido Juan Guzmán, cuya cabeza está pregonada y vale cien onzas, utiliza el recurso de la disimulación o "dissimulatio", que consiste en la sustitución de un pensamiento por otro, ocultando la verdadera opinión que le sugiere el madrinazgo de la monja:

Yo confieso mi admiración por aquella noble abadesa que había sabido ser su madrina sin dejar de ser una santa. A mí seguramente habríame tentado el diablo, porque el capitán de los plateados tenía el gesto dominador y galán con que aparecen en los retratos antiguos los capitanes del Renacimiento: Era hermoso como un bastardo de César Borgia. $(S E, 66)$

El Marqués es un hidalgo, con un antiguo y rancio abolengo. Este orgullo de casta se lo otorga la tradición, está socialmente sancionado y le pertenece por derecho propio, por ser miembro de la aristocracia española:

-¡Quien heredó grandeza, grandeza muestra!...Y es de ascendencia de reyes la de nuestro querido Marqués!

El viejo dandy repuso con una sonrisa de amable ironía: 
-De reyes y de papas... En lo antiguo, mi familia tuvo enlace con la del Cardenal Rodrigo de Borgia. (LCC, 98)

Su distinguida prosapia le da todo el derecho de formar parte de la corte del Rey. Como hidalgo, hereda privilegios y obligaciones: debe servir al rey en la paz y en la guerra, y defender al vasallo. Su condición de hidalguía le permite muchas prebendas, como el de no arrodillarse ante el mismo Dios en la misa:

Yo, como caballero santiaguista, recé mis oraciones dispensado de arrodillarme, por el fuero que tenemos de canónigos agustinos. $(S E, 58)$

Asimismo, “...es privilegio de los Marqueses de Bradomín ser recibidos con palio en las feligresías de San Rosendo de Lantañón, Santa Baya de Cristamilde y San Miguel de Deiro." (SO, 107), y hasta con campanas, como afirma su tío don Juan Manuel Montenegro.

No obstante, Bradomín no se priva de expresarse sarcásticamente sobre la manera como se conformó en algunos casos la nobleza española. En la siguiente secuencia se denuncia la forma como se obtenía la condición de hidalgo y se fundaban los mayorazgos. Naturalmente, esto pertenece a la historia nobiliaria de España:

Juan de Guzmán en el siglo XVI hubiera conquistado su Real Ejecutoria de Hidalguía peleando bajo las banderas de Hernán Cortés. Acaso entonces nos dejase una hermosa memoria de aquel capitán de bandoleros con aliento caballeresco, porque parecía nacido para ilustrar su nombre en las Indias saqueando ciudades, violando princesas y esclavizando emperadores. (...) Levantaría una torre, fundaría un mayorazgo con licencia del Señor Rey, y al morir tendría noble enterramiento en la iglesia de algún monasterio. ( $S E, 66)$

Esta sociedad de la que forma parte no le merece, por lo general, mayor respeto, como puede deducirse de este juicio sobre las mujeres cortesanas:

Dios mediante haría como las gentiles marquesas de mi tiempo que ahora se confiesan todos los viernes, después de haber pecado todos los días. Por cierto que algunas se han arrepentido todavía bellas y tentadoras, olvidando que basta un punto de contrición al sentir cercana la vejez. $(S E, 43)$

En el estamento social al que pertenece Bradomín, los nobles están por encima de los clérigos, a menos que éstos también sean de la nobleza. Cuando el Obispo de Urgel le da la bienvenida, le contesta "con señoril condescendencia, como si fuese un capellán de mi casa el Obispo de la Seo de Urgel":

-¡Bien hallado, Ilustrísimo señor!

Y con una reverencia más cortesana que piadosa, besé la pastoral amatista. $(S I, 136)$ 
Incluso llega a burlarse, como el engaño a que somete a los teólogos que le solicitan noticias del Santo Padre:

Los graves teólogos hicieron corro para escuchar mis nuevas, y como era muy poco lo que podía decirles, tuve que inventar en honor suyo toda una leyenda piadosa y milagrera: ¡Su Santidad recobrando la lozanía juvenil por medio de una reliquia! El Prior con el rostro resplandeciente de fe, me preguntó:

-¿De qué santo era, hijo mío?

-De un santo de mi familia.

Todos se inclinaron como si yo fuese el santo. $(S P, 17)$

Cabe preguntarse si por "lozanía" entiende Bradomín lo mismo que la bruja quería que él perdiera, a saber, su virilidad, con lo que el texto tendría entonces una connotación sexual y profana.

\section{El racismo en el Marqués de Bradomín}

El tema del racismo a la universalidad del ser humano, sin distinción de razas. Este valor universal del hombre sustenta el mandamiento mosaico referente a amar al prójimo. El pueblo español, fundido en el crisol de múltiples etnias, por paradoja, ha sido registrado históricamente como racista (al menos de los siglos XVI al XIX), aunque se defina como eminentemente católico. El Marqués de Bradomín no es la excepción: hombre de su tiempo, manifiesta su desprecio a ciertas etnias: los negros, los sajones y los judíos. No hay que olvidar que las Sonatas se escriben en un momento en que se plantea la europeización de España, con lo que el tema del racismo cobra gran actualidad en relación con los problemas de la Península.

Bradomín se refiere en términos peyorativos respecto del negro sacrificador de tiburones que va en la fragata La Dalila, por el cual la Niña Chole siente "ese desdén patricio que las criollas opulentas sienten por los negros": tiene "la testa chata y lanuda"; "labios hidrópicos"; "abultados labios de gigante" ( $S E, 45)$ que esbozan "una sonrisa de ogro avaro y sensual"; toma el cuchillo entre los dientes "como un perro de Terranova" (SE, 52), y silba "aires cargados de religioso sopor, una música compuesta solamente de tres notas tristes, con que los magnetizadores de algunas tribus salvajes adormecen a las grandes culebras". (SE, 45)

De modo similar se pronuncia respecto del negro liberto, casado con una andaluza que había sido doncella de la Niña Chole. Sus ojos poseen "una mansedumbre verdaderamente animal" ( $S E, 73)$, y una voz "lastimera, resignada, llena de penas. Verdadera voz de siervo". (SE, 73) Este hombre se conduele de que su esposa le sea infiel, no con blancos, sino con negros, lo cual evidencia que aun los mismos negros desprecian su propia raza:

No le dolía el engaño por la afrenta de hacerle cornudo, sino por la baja elección que la andaluza hacía: Era celoso intermitente, como ocurre con la gente cortesana que medra de sus mujeres. El duque de Saint Simon le hubiera loado en sus Memorias, con aquel delicado juicio que muestra hablando de España, cuando se desvanece en un éxtasis, ante el contenido moral de estas dos palabras: Cornudo Consentido. $(S E, 73)$ 
Obsérvese ahora la actitud racista respecto de la etnia sajona, que manifiesta cuando embarca en Londres a bordo de la fragata inglesa La Dalila. El pasaje de la fragata se compone de "herejes y mercaderes":

¡Ojos perjuros y barbas de azafrán! La raza sajona es la más despreciable de la tierra. Yo contemplando sus pugilatos grotescos y pueriles sobre la cubierta de la fragata, he sentido un nuevo matiz de vergüenza: la vergüenza zoológica. $(S E, 44)$

Así como la raza negra le merece calificativos zoomórficos y deleznables, "aquella taifa luterana" $(S E, 44)$ le provoca desprecio absoluto. Las apreciaciones en torno de las etnias sajona y judía tienen como trasfondo razones históricas, mezcladas con la intransigencia en materia religiosa:

Mi guía, supersticioso como todos los indios, creía entender en aquel grito la palabra judío, y cuando oía esta ofensa que el pájaro le lanzaba siempre al abrir las sombrías alas, replicaba gravemente:

-iCristiano, y muy cristiano! (SE, 79)

Sin embargo, la actitud racista del Marqués de Bradomín no se generaliza a todas las etnias. La Niña Chole es "una belleza bronceada, exótica, con esa gracia extraña y ondulante de las razas nómadas"; posee "esa quietud extática y sagrada de la raza maya, raza tan antigua, tan noble, $\tan$ misteriosa, que parece haber emigrado del fondo de la Asiria." $(S E, 46)$

El objeto de las normas sociales son los seres que rodean al sujeto, en relación con los fines individuales y comunes. El fundamento de todas las leyes sociales de valor moral es la estimación del prójimo como a sí mismo. Este valor es considerado por la moral cristiana como un precepto, con la diferencia de que el cristianismo manda el amor, no sólo la estimación. El cumplimiento de tal deber está muy lejos de las intenciones de Bradomín. No sólo se considera en un estrato racial superior a la de las etnias mencionadas, sino que, además, descalifica otras creencias religiosas que no sean la suya propia, oponiendo su libertad de decisión a la libertad de decidir que tienen los demás seres. En todo caso, el racismo es un antivalor que contraviene normas sociales y religiosas, en relación con las cuales Bradomín es un transgresor, particularmente a partir de su definición de católico.

\section{Conclusiones}

La vida espiritual no es nunca únicamente cosa del individuo, sino que lo que constituye la persona lo toma de la esfera espiritual dentro de la que se desarrolla, que es el espíritu histórico circundante. El Marqués de Bradomín no es una excepción; hombre de su tiempo, su circunstancia vital permite distinguir su pertenencia a ese espíritu histórico que lo entorna.

La lente irónica de Bradomín pone de manifiesto que la sociedad en la que se desenvuelve es falsa e hipócrita, inclinada al perenne juego del enmascaramiento, con un código de valores impracticable en la medida en que se queda en el plano de la apariencia. Tanto la casta 
nobiliaria como la clerecía son cuestionadas, y hasta denunciadas como inauténticas, y no le merecen mayor respeto. Respecto de la discriminación racial y religiosa del Marqués obedecen más a patrones culturales preestablecidos que a una auténtica toma de posición del ser frente al mundo, pero constituyen una subversión de los códigos éticos y cristianos que reconoce como válidos.

Aunque se han omitido otros aspectos que podrían confirmar las Sonatas como reflejo de la realidad española, como la presencia de una ideología política claramente distinguible -la monarquía, el carlismo-; la estratificación social, el militarismo o la religión, entre otros, los pocos ejemplos antes mencionados demuestran el carácter subversivo y de ruptura que manifiesta la visión de mundo del Marqués de Bradomín, a partir de su toma de posición y las relaciones que establece con los demás y la valoración consciente de su ámbito humano. Sin embargo, es necesario aclarar que la máscara irónica y burlona de su discurso tiende barreras de ocultación que imposibilitan saber cuál es su verdadera apreciación de las cosas, que permanece por eso mismo en el plano de la indiferenciación.

Cabe señalar que la indagación de la visión de mundo del Marqués desmiente las apreciaciones de algunos críticos que consideraron las Sonatas como un simple ejercicio de estilo preciosista, sin otro propósito que el arte por el arte. Por el contrario, el estilo modernista de las Sonatas permite desarrollar con magnífica precisión estética un acérrimo sentido de crítica social que no escapa a la comprensión analítica.

Por último, se destaca como una constante la absoluta vigencia de Valle-Inclán, que se refleja en el hecho de que toda su producción se reedita ininterrumpidamente; en su actualidad y en una revalorización creciente de su obra, posibilitada por múltiples razones, como la perspectiva histórica, los cambios en la concepción de criterios estéticos, ideológicos y valorativos, y su lugar incuestionable en la historia de la literatura.

\section{Notas}

1. José Ortega y Gasset. "La Sonata de Estío de don Ramón del Valle-Inclán". Obras completas. $5^{\circ}$ ed. Vol I Gredos, 1961 (p. 25).

2. Antonio Risco. La estética de Valle-Inclán. Madrid: Gredos, 1979 (p. 13).

3. Ibid., p. 38.

4. Eugenio de Nora. La novela española contemporánea (1898-1927). Madrid: Gredos, 1958 (p. 49).

5. Allen Phillips. Estudio preliminar a las Sonatas. México: Porrúa, 1975 (p. XXVI).

6. Melchor Fernández Almagro. Vida y literatura de Valle-Inclán. Madrid: Taurus Ediciones, S.A., 1966 (p. $82)$.

7. Summer Greenfield. Don Ramón del Valle-Inclán: Anatomía de un teatro problemático. Caracas: Ed. Fundamentos, 1972 (p. 20).

8. Carlos Seco Serrano. "Valle-Inclán y la España oficial”. Revista de Occidente, Núm. 44-45, Nov-Dic, 1966 (p. 205). 
9. José Antonio Maravall. "La imagen de la sociedad arcaica en Valle-Inclán". Cuadernos hispanoamericanos, $\mathrm{N}^{\circ} 283$. Enero, 1974 (p. 226).

10. Rodolfo Cardona y Anthony Zahareas. Visión del esperpento. Teoría y práctica de los esperpentos de Valle-Inclán. Madrid: Castalia, 1970 (p. 17).

11. Helena Beristáin. Diccionario de Retórica y Poética. México: Porrúa, 1985.

12. María Pérez Yglesias. "Ironía, dependencia y humor en la producción significante latinoamericana”. Revista de Filología y Lingüística de la UCR, Vol 9, N 1, mar-set, 1983 (p. 155).

13. Id. ibid., p. 158.

\section{Bibliografía}

Beristáin, Helena. 1985. Diccionario de Retórica y Poética. México: Porrúa.

Buero Vallejo, Antonio. 1966. "De rodillas, de pie, en el aire". Revista de Occidente. (44).(45).

Cardona, Rodolfo y Anthony Zahareas. 1970. Visión del esperpento. Teoría y práctica de los esperpentos de Valle-Inclán. Madrid: Castalia.

Cox Flynn, Gerard. 1961. “The adversary Bradomín”. Hispanic Review. 29.

1964. "The bagatela of Ramón del Valle-Inclán". Hispanic Review. 32.

Díaz-Plaja, Guillermo. 1972. Las estéticas de Valle-Inclán. Madrid: Gredos.

Dougherty, Dru. 1987. “Theater and eroticism: Valle-Inclán's Farsa y licencia de la reina castiza”. Hispanic Review. 55. (1).

Fernández Almagro, Melchor. 1966. Vida y Literatura de Valle-Inclán. Madrid: Taurus Ediciones, S.A.

García de la Torre, José Manuel. 1986. "La evolución lingüística de Valle-Inclán”. Cuadernos Hispanoamericanos. Homenaje a Don Ramón del Valle-Inclán. (438).

García Velasco, José Lius. 1986."Fantasmas de la bohemia”. Revista de Occidente. (59).

García Pelayo, Manuel. 1974."Sobre el mundo social en la literatura de Valle-nclán". Cuadernos Hispanoamericanos. (283).

Gómez de la Serna, Gaspar. 1966. "Del hidalgo al esperpento, pasando por en dandy". Cuadernos Hispanoamericanos. Homenaje a Valle-Inclán. 67.(199) (200). 
1959. Don Ramón María del Valle-Inclán. Madrid: Austral,

Greenfield. Sumner. 1972. Don Ramón del Valle-Inclán: Anatomía de un teatro problemático. Caracas: Ed. Fundamentos .

Lavaud, Elaine. 1974. "Un prologue et un article oublies: Valle-Inclán, theorician du modernisme”. Bulletin Hispanic. (76).

Maravall, José Antonio. 1974.'La imagen de la sociedad arcaica en Valle-Inclán”. Cuadernos Hispanoamericanos. (283).

Nora, Eugenio de. 1958. La novela española contemporánea (1898-1927). Madrid: Gredos.

Ortega y Gasset, José. 1961. "La Sonata de Estío de don Ramón del Valle-Inclán”. Obras Completas. Madrid: Gredos. 1.

Pérez Yglesias, María. 1983.’'Ironía, dependencia y humor en la producción significante latinoamericana". Revista de Filología y Lingüística de la UCR, 9.(1).

Phillips, Allen. 1975. Estudio preliminar a las Sonatas. México: Porrúa.

Predmore, Michael. 1988. "Satire un the Sonata de Primavera" . Hispanic Review. 56 (3)

Risco, Antonio. 1977. El demiurgo y su mundo. Madrid: Gredos.

1979. La estética de Valle-Inclán. Madrid: Gredos.

Seco Serrano, Carlos. 1966. "Valle-Inclán y la España oficial”. Revista de Occidente. (44) (45)

Speratti-Piñero, Emma Susana. 1959. "Génesis y evolución de Sonata de Otoño". Revista Hispánica Moderna. (1) (2).

Valis, Noel M. 1989. "The novel as Feminine Entrapment: Valle-Inclán's Sonata de otoño". Modern Language Notes. 104 (2).

Valle-Inclán, Don Ramón del. 1975. Sonata de primavera. Sonata de Estío. Sonata de otoño. Sonata de invierno. México: Porrúa.

Zamora Vicente, Alonso. 1958. Las Sonatas de Valle-Inclán. Madrid: Gredos. 